\title{
A Perspectiva Do Processo Saúde/Doença Na Promoção de Saúde Da População
}

THE PERSPECTIVE OF THE HEALTH/ILLNESS PROCESS IN THE PROMOTION OF HEALTH OF THE POPULATION

\author{
Liane Teresinha Schuh Pauli ${ }^{*}$ \\ Scheila Cristina Artus ${ }^{(*)}$ \\ Rachelle A. A. Balbinot ${ }^{(* *)}$
}

\section{RESUMO}

A verificação da importância do Processo Saúde/Doença e a perspectiva acerca da promoção e prevenção da saúde na população que procura atendimento médico num posto de saúde de um município do Vale do Taqua$\mathrm{ri}$ - RS, verificado em pesquisa quali-quantitativa que utilizou o método exploratório descritivo, viabilizado por um questionário com questões abertas e fechadas, foram objetivo e método desta pesquisa. Após a análise dos dados, evidenciou-se que a população entende corretamente o que significa prevenção da saúde, mas por algum motivo, seja falta de interesse, motivação ou educação, procura o serviço de saúde somente após estar acometido por alguma patologia. Observou-se que $97,22 \%$ dos entrevistados, não sabe o que significa promoção da saúde. A população tem noção do que é prevenção, porém há uma carência de orientações sobre sua importância e sobre o que seja promoção da saúde, bem como a realização de um trabalho de motivação e educação por parte das equipes multiprofissionais.

$\left(^{*}\right)$ Enfermeira Mestre em Desenvolvimento Regional da Universidade de Santa Cruz do Sul UNISC - RS, Coordenadora do Núcleo Regional de Educação em Saúde Coletiva da 13a Coordenadoria Regional de Saúde da Secretaria Estadual de Saúde do Rio Grande do Sul. E-mail: pauli@unisc.br.

$\left.{ }^{* \star}\right)$ Enfermeira da Secretaria Municipal de Saúde de Venâncio Aires - RS.

$\left(^{\star \star \star}\right)$ Advogada Mestre em Direito pela Universidade Federal de Santa Catarina/UFSC e Doutoranda pelo Programa de Pós-Graduação em Integração da América Latina/PROLAM-USP. Email: balbinot @ipejur.com.br. Recebido em 6.6.2003. Reapresentado em 21.8.2003. Aprovado em 21.9.2003. 


\section{Descritores}

Processo Saúde/Doença, Promoção de Saúde, Educação em Saúde.

\section{ABSTRACT}

The present research paper discusses the importance of the Health/ IIIness Process, objecting to identify the knowledge about the promotion and prevention of the health in the people who look for help with a doctor, in the public health care system of a town in the Vale do Taquari - RS. The research is based on quality and quantity, using the explanatory and describing method. Open and closed questions were made, to the feasibility of the data collection. After administering the instrument, data analyses were done. It was proven that the population understands correctly what health prevention means, but for some reason as lack of interest, motivation or education, the people seeks for the public health care system, only after being ill. Another important topic is that $97,22 \%$ of interviewees do not know what health promotion means. In short, the population is reasonably aware of what prevention is. However, there is a lack of orientation about its importance and about what health promotion is. In addition, there is a lack of motivational and educational campaigns done by multi - professional teams.

\section{Key-words}

Health/llness Process, promotion in health, education in health.

O ser humano está permanentemente variando seu permeável estado de saúde e de doença, desde o seu nascimento até a sua morte; campo de necessidades humanas abrangentes, que se fazem acompanhar por certos interesses político-econômicos e fatores biológicos, culturais e sociais. O campo da saúde tem sido alvo mundial de muitos estudos devidos às mudanças que vêm ocorrendo em várias destas frentes de análise. $O$ conceito de saúde vem sofrendo modificações em sua percepção cada vez mais ampla, incluindo-se questões como prevenção de doenças e promoção de saúde, qualidade de vida e bem-estar social, entre outras. No campo relativo ao direito, o conceito de saúde "engloba tanto a ausência de doença, quanto o bem-estar, enquanto derivado das políticas públicas que o tem por objetivo, seja apenas a política, seja sua implementação, traduzida na garantia de acesso - universal e igualitário - às ações e serviços com o mesmo objetivo (CF. art. 196 ${ }^{(1)}$ ) (DALLARI, 1995, p. 30). Concepções que

(1) Art. 196. A saúde é direito de todos e dever do Estado, garantido mediante políticas sociais e econômicas que visem à redução do risco de doença e de outros agravos e ao acesso universal e igualitário às ações e serviços para sua promoção, proteção e recuperação. BRASIL. Constituição da República Federativa do Brasil. $2^{a}$ ed. rev. atual. ampl. São Paulo: RT, 2000. Yussef Said Cahali (org.). 
solicitam a redefinição da organização e do funcionamento dos sistemas e dos serviços de saúde que atuam na abrangência municipal, base do Sistema Único de Saúde.

Os seres humanos possuem necessidades que são decorrentes do processo "saúde-doença", conforme Seixas, em 1999, "que envolve desequilíbrios ou inadequações nas suas ações e reações de crescimento e desenvolvimento e nas ações e reações a agentes e estímulos exteriores". A definição de necessidades vem progressivamente se transformando na sociedade conforme se desenvolve o processo produtivo, sua organização nas inter-relações deste processo e nas variações demográficas, tanto em questões de dimensão como em urbanização.

A teoria da multicausalidade demonstra que a produção ou determinação social do processo de saúde e doença de uma sociedade depende também da cultura e do modo de organização desta sociedade, em que ela mesma produz seu processo de variação exigindo da saúde pública e das políticas públicas um processo de intervenção diferenciado. Seguindo-se os preceitos dos campos de atenção à saúde da NOB-SUS/96, enquadrase o espectro de ações nos chamados níveis de atenção à saúde, representados pela promoção, pela proteção e pela recuperação, sendo que estes três pilares encontram-se previstos nos arts. 196, da CF, e $2^{\circ}$, $\S 2^{\circ}$, da Lei n. 8.080/90, observando-se sempre como prioridade o caráter preventivo. O processo circula neste gradiente progressivamente diferenciado interagindo e se transformando simultaneamente. Sob este viés as ações de saúde devem ser integradas, levando-se em consideração, os indivíduos da população mais expostos a fatores de risco. No campo da saúde podemos observar a inter-relação de fatores como os biológicos ou individuais, estilo de vida, ambiente all round e a forma de organização dos serviços de saúde.

Um sistema de saúde que atende apenas a demanda espontânea utiliza de modo ineficiente os recursos, além de produzir baixo impacto sobre os dados epidemiológicos desta comunidade. Estratégia iniciada na década de 70, os programas de saúde, apareceram na tentativa de modificar o modelo de assistência a demanda clínica e aumentar a efetividade das ações em saúde, reorganizando as práticas do sistema, criticando o sistema vigente. $O$ modelo de atenção, devidamente adequado ao meio social e sanitário a que se propõe, fundamentado historicamente, deve ter como objetivo mor as ações de intervenção sobre o processo saúde/doença desta comunidade.

Levando-se em consideração as relações sociais, os valores e os interesses dos diferentes grupos sociais, cultural, econômica e cientificamente, os modelos de atenção a saúde de cada comunidade, são caracterizados pelo seu processo político. Sendo uma prática dinâmica, que deve buscar, conforme as bases do SUS, a integralidade das ações, o processo político das quais depende o devido modelo de atenção proposto para a 
comunidade, deve seguir as diretrizes constitucionais, as normas legais do sistema brasileiro, respeitar a cultura e a historicidade, seguindo preceitos culturais e de percepção diante do conceito de saúde deste conjunto social. Conforme 0 art. 198 da Constituição Federal, as diretrizes são três: descentralização, atendimento integral e participação da comunidade.

A política de saúde nacional que utiliza a descentralização e centra a área decisória no gestor municipal, com participação social, busca a eficiência do sistema adequando suas questões gerenciais a realidade e as questões que se transformam dinamicamente na sociedade. $O$ indivíduo, nestes tempos, passou de uma atuação passiva para um modo ativo de participar das questões gerenciais e de condutas individuais e de consciência sobre o seu próprio processo de saúde/doença, tendo oportunidade de reflexionar frente à resolutividade das ações e dos serviços de saúde do seu município de região, apoiando a implantação e viabilização do Sistema Único de Saúde. É importante ressaltar que o Sistema Único de Saúde, em determinação na sua Lei Orgânica (Lei n. 8.080/90), dispõe no art. $1^{\circ}$ que "as ações e serviços de saúde, executados isolada ou conjuntamente, em caráter permanente ou eventual, por pessoas naturais ou jurídicas de direito público ou privado", ou seja, independentemente do caráter do prestador (público ou privado), as atividades que referem este artigo serão sempre realizadas em conformidade com o que está expresso nos princípios que regem o SUS.

A cooperação técnica e financeira das quais a gestão municipal necessita deve ser prestada pelos níveis estadual e federal. À esfera estadual cabe, entre outras, a harmonização, a modernização, a integração e a mediação da relação entre os sistemas municipais, e a assessoria diante da programação pactuada e integrada e outros impasses em frente a sua operacionalização; conforme a NOB-SUS 01/96 um de seus papéis é "promover as condições e incentivar o poder municipal para que assuma a gestão da atenção a saúde de seus munícipes, sempre na perspectiva da atenção integral".

Intersetorialidade, numa visão de integração dos vários segmentos que compõe o governo municipal, seguindo os mesmos preceitos em relação à saúde e propondo prioridades. Necessidade de profissionais com boa capacitação técnica, com autonomia de ação e liberdade de atuação voltados para mesmos objetivos, criando uma cultura organizacional intersetorial de resolutividade dos problemas, observando a teoria da multicausalidade do processo saúde/doença.

As dificuldades ideológicas que perpassam a implantação do SUS, podem ser resumidas em questões de racionalização da administração municipal. Conceitos como de cidadania, de equidade, de universalidade e integralidade não estão presentes no dia a dia das pessoas, dos cidadãos, certamente dificultando a devida implantação do sistema, conforme preconiza suas normas. Outras questões como a contratação e capacitação de 
recursos humanos, compra de materiais, e a burocratização a que são submetidas as Secretarias Municipais dificultam ainda mais o cumprimento das diretrizes do sistema, exigindo dos gestores o uso criativo de estratégias para uma efetiva gestão na saúde pública municipal. A NOAS-SUS 01/2001, apregoa, entre tantas orientações e regras, que "outros mecanismos de controle e avaliação devem ser adotados pelo gestor público, como o acompanhamento dos orçamentos públicos em saúde, a análise da coerência entre a programação, a produção e o faturamento apresentados, assim como as discussões sobre resolutividade regional são questões que muito lentamente são propostas para incrementação de tecnologia e capacitação e de discussões dos gestores municipais.

A autonomia buscada no conhecimento e na crítica, a consciência de ser cidadão, as condutas éticas e a responsabilidade pela representação política dos munícipes são práticas capazes de intervir no processo saúde/ doença por meio de ações integrais em saúde fundamentadas na cultura da promoção, proteção e recuperação, envolvendo valores, política e modernização das práticas adminstrativas e gerenciais, buscando a mudança do perfil epidemiológico municipal para melhoria da qualidade de vida das pessoas.

De acordo com a Organização Mundial da Saúde, apud Kawamoto (1995; p.11), "a saúde é um estado de completo bem-estar físico, mental e social e não a mera ausência de moléstia ou enfermidade". De forma errada, tenta-se definir saúde, como sendo a não doença, pois certos sistemas de saúde baseiam-se no conceito de que se obtém saúde erradicando-se as doenças.

Conforme a Lei n. 8.080/90, a saúde é resultante da influência dos fatores socioeconômico-culturais: alimentação, habitação, educação, renda, meio ambiente, trabalho, transporte, emprego, lazer, liberdade de acesso a serviços de saúde. Esses fatores podem gerar grandes desigualdades nos níveis de vida, que irão interferir na saúde individual e coletiva. (Brasil, 1990).

Esta situação é também enfatizada por Carvalho e Santos (2002, p. 42), "A própria reforma sanitária, preconizada na 8 Conferência Nacional de Saúde, enfaticamente colocou essa questão. Não se pode discutir a saúde independentemente de suas determinantes e condicionantes. A concepção de saúde como resultante de questões extra-setoriais mais abrangentes se contrapõe à concepção de que a doença (falta de saúde) é causa de distúrbios e desvios em outros setores".

Uma das maneiras de evitar as doenças é utilizando os meios de prevenção e a promoção, procurando os serviços de saúde, buscando orientação educacional, imunizando crianças, realizando exames preventivos. Atualmente podemos dizer que existe um provérbio na área da saúde: "prevenir é melhor que remediar". 
Estamos vivendo um momento no qual há prevenção para várias doenças. Porém, é necessário avaliarmos como esta atuação preventiva vem sendo realizada, já que os índices de problemas de saúde não estão reduzindo como o esperado perante tantas ações preventivas.

$O$ ato de prevenir, impedir, precaver doenças é amplo e complexo, pois exige educação, conscientização e participação popular. A participação popular prevista nos arts. 198, III, e 194, VII, da Constituição Federal e art. 77, $\S 3^{\circ}$, do ADCT (Ato das Disposições Constitucionais Transitóras) "é a expressão mais viva da participação da sociedade nas decisões tomadas pelo Estado no interesse geral, ou seja, da participação popular no exercício do poder político" (Carvalho e Santos, 2002, p. 291). Um programa de saúde preventiva tem como objetivo educar a população, fazer com que as pessoas pensem e ajam de maneira diferente a fim de evitar as doenças.

Se existem tantos programas preventivos de saúde, por que alguns índices de doenças não diminuem? A educação na área da saúde não pode ser uma imposição de mudança, deve contribuir para que as pessoas adquiram novos conhecimentos, que precisam ser incorporados livremente e por iniciativa própria. É necessário tomar consciência para agir.

No campo das necessidades ou desejos, aspirações e sonhos factíveis por conhecimentos possíveis e disponíveis, caracterizadas individualmente, as necessidades não são naturalmente explicitadas. Para Pereira (2000), "a política de satisfação de necessidades embutidas numa questão socialmente engendrada constitui uma arena incontestável de conflitos de interesses". O próprio indivíduo desenvolve um mecanismo natural de se autocuidar, que pode consciente ou inconscientemente estar protegendo ou promovendo seu bem-estar físico ou psíquico, necessitando algumas vezes de intervenção por meio do conhecimento de outros ou medicamentosa para recuperar o seu estado de saúde. Este processo muitas vezes pode tornar o homem dependente de certos serviços ou pessoas.

Deste modo, caracteriza-se o mecanismo de mercado em que as necessidades de saúde podem ser trocadas por conhecimentos científicos e de tecnologia. Seixas (1999), descreve este processo mostrando que "vão se interdependendo, e inter-relacionando, complementar ou competitivamente, configurando sempre uma realidade complexa e com graus de suficiência e de eficiência variáveis, no tocante às suas finalidades específicas de saúde". Este conjunto de fatores, agregados a uma população forma o sistema de saúde, onde a própria sociedade produz o seu processo de variação.

Os profissionais da saúde têm um papel fundamental no processo de prevenção e educação da população. É preciso estar inserido, conhecer profundamente as situações de vida, participar ativamente da comunidade. A prevenção é feita no dia-a-dia, por todos, por meio da troca de informações e conhecimentos. 
O interesse em realizar o presente trabalho surgiu a partir da curiosidade em saber porque as pessoas "esperam ficar doentes" para depois procurar o serviço de saúde. É importante ressaltar que o tema escolhido sempre foi de interesse. Dessa forma, iremos abordar o conhecimento da população que freqüenta o Posto de Saúde Central de um município do Vale do Taquari - RS, em relação à prevenção e promoção da saúde e por que as pessoas só procuram o serviço de saúde depois que já estão doentes ou apresentam algum sintoma de doença. Assim, pretendemos perceber 0 conhecimento que a população possui a respeito de prevenção e promoção, verificar se recebem algum tipo de orientação e ou informação sobre sua importância e avaliar o tipo de orientações que são fornecidas pela equipe de saúde.

Segundo Lebrão (1997), o interesse do homem pela doença é tão antigo como ele mesmo, e a razão para isso parece muito simples: quase ninguém escapa à experiência de adoecer uma ou mais vezes na vida.

Quando conceituamos doença o fazemos, de modo geral, estabelecendo uma relação direta entre as nossas limitações para o desempenho de atividades cotidianas e um estado de mal físico e/ou emocional. Conseqüentemente, as nossas concepções sobre saúde assumem uma forte conotação de "ausência de doença" e daqueles traços que the são característicos como o sofrimento, a dor e a morte. Embora sejam concepções simplistas, elas são mitos usados. (Fiocruz, 1998).

$\mathrm{Na}$ prática clínica, as pessoas são examinadas e rotuladas como sadias ou doentes, em função de julgamentos baseados em resultados de exames laboratoriais que informam a presença ou ausência de anormalidades. Em inquéritos de morbidade, um processo semelhante de diagnóstico pode ser empregado, utilizando-se o instrumental clínico clássico: história, exame físico e testes laboratoriais complementares (Pereira, 1995).

Segundo Ceccim (1998), saúde e doença não são conceitos definitivos, tampouco são conceitos em oposição, mas ambos dizem respeito à sobrevivência, à qualidade de vida ou à própria produção da vida. Para refletir sobre como se concebe o que seja saúde e doença a partir do século $X X$, podemos pensar em três grandes perspectivas paradigmáticas: a da medicalização, a da atenção primária e a da defesa da vida.

A institucionalização da medicina acentuou o caráter medicalizante da atenção de saúde, centrando as noções de saúde em torno da prática médica, particularmente da prática hospitalar e de alto consumo tecnológico. Podemos observar que a medicalização repercutiu em noções específicas de corpo: o corpo humano como uma máquina, por exemplo, como se pudessem ser analisadas em peças, mecanismos, engrenagens, sistemas de encaixe e disjunção, alimentação energética, etc. Saúde passava a ser o bom funcionamento da máquina, e a doença sua falha, o seu defeito ou o seu 
desgaste mecânico. A intervenção terapêutica seria a prática restauradora, corretiva ou de retorno ao bom funcionamento.

O prestígio do diagnóstico médico das doenças e o prestígio da terapêutica curativa se coadunam com a dependência do ato médico para a promoção da saúde, onde saúde passa a ser sinônimo de problema médico. A própria prevenção também termina instituída como especialidade médica: a medicina preventiva, de tal sorte que só pode ser compreendida mediante o conhecimento anátomo - clínico ou fisiológico.

Em 1978, uma grande virada parece se armar contra a medicalização. Em lugar da assistência médica como estratégia de atenção à saúde, começa a vigorar um novo discurso/novo conceito: a Atenção Primária de Saúde. Para renovar a assistência médica é proposto o estabelecimento da maior proximidade com as famílias e comunidades locais na prática de atendimento à saúde e a doença e o respeito à cultura.

A Atenção Primária de Saúde não realizou a desmedicalização da medicina, mas voltou atenção da saúde às áreas rurais e de periferia urbana, dando cobertura assistencial de saúde às populações desassistidas e desenvolvendo parte do conhecimento em saúde da população.

Embora não desmedicalizasse as concepções de saúde e doença, a Atenção Primária de Saúde ajudou a desflexnerizar a medicina, porque propunha a integração da formação com o atendimento quotidiano de saúde nas comunidades locais, a expansão da formação e ocupação do pessoal de nível médio (auxiliares e técnicos), a estruturação de um programa setorial de saúde nas políticas públicas de programas de saúde coletiva e de saúde da família a partir das ações de atendimento individual e a introdução da participação popular em saúde (Dallari, 1985). Conforme Carvalho e Santos (2002, p. 293), "No SUS, a participação do cidadão em sua gestão pressupõe, ainda, o exercício do controle dos atos dos administradores públicos, uma vez que a Lei n. 8.142/90 reza que os conselhos de saúde atuam na formulação de estratégias e no controle da execução da política de saúde, inclusive nos aspectos econômicos e financeiros ( $§ 2^{\circ}$ do art. $1^{\circ}$ )".

A Atenção Primária de Saúde destaca a noção de saúde da família, de atendimento domiciliar e de atividades educativas. Na prática, disseminou-se como alternativa para a falta de serviços básicos de acordo com as necessidades populares, seja em saúde, educação, habitação ou saneamento.

Além dos fatores fisiopatológicos, fatores não fisiológicos desencadeiam a busca de atenção de saúde e representam conteúdos socioculturais relativos à sensação de adoecimento e não ao conceito médico de doença. Não é somente por patologias transmissíveis que as pessoas requerem atendimento de saúde, nem tampouco porque haja acometimento de órgãos corporais. Os momentos em que se decide pela busca de um 
serviço não são enquadráveis em hierarquia de gravidade ou de complexidade técnicas, nem tampouco pela presença de sintomas físicos.

Atualmente, no Brasil, a integralidade da atenção de saúde é um dos princípios que regem, moral e legalmente, as ações e serviços de saúde (Lei Orgânica da Saúde, 1990). Essa atenção integral é entendida como a articulação/integração/simultaneidade das ações e dos serviços, preventivos e curativos, individuais e coletivos, exigidos para cada caso em todos os níveis de complexidade do Sistema de Saúde (Campos, 1991). Partindo de uma concepção ampla do processo saúde doença e de seus determinantes, propõe a articulação de saberes técnicos e populares, e a mobilização de recursos institucionais e comunitários, públicos e privados, para seu enfrentamento e resolução.

A carta de Ottawa (1986), um dos documentos fundadores da promoção da saúde atual, está associada a um conjunto de valores: qualidade de vida, saúde, solidariedade, equidade, democracia, cidadania, desenvolvimento, participação e parceria, entre outros. Refere-se também a uma combinação de estratégias: ações do estado, da comunidade, de indivíduos, do sistema de saúde e de parcerias intersetoriais. Trabalha com a idéia de responsabilização múltipla, seja pelos problemas, seja pelas soluções propostas para os mesmos.

O conceito moderno de promoção da saúde surgiu e se desenvolveu de forma mais vigorosa nos últimos vinte anos. Quatro importantes Conferências Internacionais sobre promoção da saúde, realizadas nos últimos 12 anos - em Ottawa (WHO, 1986), Adelaide (WHO, 1988), Sundsvall (WHO, 1991) e Jacarta (WHO, 1997), desenvolveram as bases conceituais e políticas da promoção da saúde.

Segundo Pereira (1995), etiologia e prevenção são aspectos muito relacionados, o melhor conhecimento do primeiro indica os melhores caminhos para concretizar o segundo. A etiologia na fase pré-patológica: nesta fase os eventos que ocorrem em época ainda anterior à resposta biológica inicial do organismo. A etiologia na fase patológica encontram-se os processos que ocorrem no interior do corpo humano e que se sucedem a partir da resposta orgânica inicial; os quais são responsabilizados pela exteriorização da afecção.

Segundo Rouquayrol e Filho (1999), prevenção é abrangente, incluindo a ação dos profissionais em saúde, das quais cabe uma importante parcela da ação preventiva: a decisão técnica, a ação direta e da ação educativa.

No período de pré-patogênese, a prevenção consiste de medidas destinadas a promover uma saúde geral e de elementos protetores específicos. Este inclui imunização, saneamento ambiental e proteção contra acidentes e riscos ocupacionais. Esta é a prevenção em seu sentido convencio- 
nal. Estas medidas mostram ser muito eficazes na redução da mortalidade e morbidade por doenças infecciosas. As medidas gerais de promoção à saúde incluem estilo de vida, fatores ambientais e biológicos e podem proporcionar a maior contribuição para posteriores reduções da mortalidade e morbidade (Forattini, 1996).

A prevenção secundária consiste principalmente no diagnóstico precoce e tratamento de doenças por meio de medidas como rastreamento e exames médicos periódicos. O diagnóstico precoce do câncer, hipertensão e doenças venéreas e outras doenças curáveis são o objetivo da prevenção secundária. Para Dever (1998), a doença já se instalou e provocou seqüelas. A prevenção terciária consiste em evitar a total incapacidade, depois que as mudanças anatômicas e fisiológicas estiverem mais ou menos estabilizadas. O objetivo é recuperar o indivíduo atingido para uma vida satisfatória e auto-suficiente. A prevenção de doenças e a promoção da saúde também representam uma oportunidade de interagir com as mudanças nesse campo e com serviços em expansão. O custo dos cuidados com a saúde tem aumentado constantemente, enquanto as taxas de ocupação hospitalar e a permanência têm diminuído. Ao mesmo tempo, as taxas de sobrevivência de muitas doenças crônicas têm aumentado, bem como a população com 65 anos ou mais. Estas duas últimas tendências indicam a necessidade crescente/óbvia da prevenção secundária e terciária. A prevenção primária representa, para os prestadores de serviço, uma oportunidade de lidar com estas e outras mudanças.

O Sistema Único de Saúde surgiu como resposta à insatisfação e descontentamento existente em relação aos direitos de cidadania, acesso, serviços e forma de organização do sistema de saúde. Nos anos 70 e 80, vários médicos, enfermeiros, donas de casa, trabalhadores de sindicatos, religiosos e funcionários dos postos e secretarias de saúde levaram adiante um movimento, o "movimento sanitário", com o objetivo de criar um novo sistema público para solucionar os inúmeros problemas encontrados no atendimento à saúde da população. O movimento orientava-se pela idéia de que todos têm direito à saúde e que o governo, juntamente com a sociedade, tem o dever de fazer o que for preciso para alcançar este objetivo. $O$ SUS resultou de um processo de lutas, mobilização, participação e esforços desenvolvidos por um grande número de pessoas.

Segundo Carvalho e Santos (2002, p. 35),

"As Constituições brasileiras anteriores não asseguravam o direito à saúde. Cabia ao Estado cuidar da assistência pública, da edição de normas de proteção à saúde pública, da prestação de assistência médica e hospitalar ao trabalhador filiado ao regime previdenciário, sem, contudo, garantir ao cidadão o direito à saúde, em seu aspecto mais abrangente que encontra definição um tanto utópica, mas aceita por muitos especialistas da saúde "como um estado de completo bem- 
estar físico, mental e social e não apenas a simples ausência de doenças e outros danos' (Organização Mundial da Saúde - (OMS), 1946)."

As diferentes situações de vida dos vários grupos populacionais geram problemas de saúde específicos, bem como riscos e/ou exposição maior ou menor a determinadas doenças, acidentes e violências. Isto significa, portanto, necessidades diferenciadas, exigindo que as ações da gestão do sistema e dos serviços de saúde sejam orientadas para atender a essas especificidades.

O Sistema Único de Saúde tem seus serviços administrados pelos governos federal, estadual e municipal e por organizações, cujo objetivo é garantir seus preceitos e a prestação de serviços gratuitos a qualquer cidadão (www.saude.gov.br). É bem verdade que o SUS, como não poderia deixar de ser, está em constante processo de aperfeiçoamento. A promoção da saúde à população estará sofrendo constantes transformações, pois, como as sociedades são dinâmicas, a cada dia surgem novas tecnologias que devem ser utilizadas para a melhoria dos serviços e das ações de saúde. Além disso, temos como condição essencial para um melhor funcionamento do SUS a participação e mobilização social em seus trabalhos. A participação da população na gestão da coisa pública ainda é recente em nosso país, mas se reveste de extrema importância, especialmente no âmbito da saúde. Conforme Cohn e Elias (2003, p. 118), "A continuidade e a generalização em grande escala do controle público na saúde, sobretudo envolvendo a participação popular, como caminho para a democratização da sociedade e para a construção da cidadania, dependem principalmente da atuação de dois atores coletivos: as administrações, nas diferentes esferas de governo, e os movimentos sociais, principalmente as organizações de cunho mais popular, como por exemplo, os movimentos de saúde". Esta participação revela a faceta democrática do nosso proclamado Estado Democrático de Direito, no qual as leis que nos regem são provenientes da nossa forma de governo, qual seja, a democracia. Segundo Carvalho e Santos (2002, p. 295), enfatizando a relevância da participação popular quanto ao processo de avaliação das ações e serviços de saúde como sendo "a manifestação mais importante do controle social: o cidadão e usuário no centro do processo de avaliação e o Estado deixando de ser o árbitro infalível do interesse coletivo, do bem comum".

Segundo Dussault (1992), as organizações de saúde devem ser flexíveis e capazes de responder as exigências mutáveis para enfrentar as mudanças das necessidades e das expectativas da sua clientela. Sendo organizações de serviços profissionais, têm de facilitar o trabalho autônomo dos prestadores e, ao mesmo tempo, garantir que esse trabalho seja coerente com os objetivos organizacionais. Isso convida a conceber organizações com a capacidade autônoma de tomar decisões rápidas em função dos seus problemas próprios e das peculiaridades do seu ambiente. A autonomia 
dos profissionais não é tanto um direito quanto uma condição necessária para a produção de serviços de boa qualidade.

O tipo de gestão deve ser aquele que reconheça o papel central dos profissionais e aceita que os profissionais trabalhem com responsabilidade. O desafio da gestão das organizações de saúde consiste em responsabilizar os prestadores pelo oferecimento de um ambiente próprio ao trabaIho multiprofissional e pela integração da participação dos usuários no processo de produção de serviços. Os gestores precisam ter capacidade intelectual e interpessoal que permita enfrentar um ambiente complexo, variável e com muitas de limitações. Deve ser capaz de entender o funcionamento de uma organização profissional, o processo de produção de serviços de saúde, a rede de relações de sua organização com o ambiente, as necessidades da comunidade e sua evolução.

Nada sugere aqui qual o tipo de profissional é mais adequado para gerir uma organização de saúde. Pode ser um profissional da saúde ou de uma outra área. O necessário é que possua as capacidades, o conhecimento, as atitudes compatíveis com as exigências da gerência desse tipo de organização. Da mesma maneira, não há um tipo único de formação. Não seria coerente em nossa descrição das características e exigências para gestão das organizações de saúde propor programas formais e padronizados da formação.

Segundo Araújo (1995), as ações de enfermagem nos diferentes níveis são diferenciadas na prevenção primária, que trabalha com promoção da saúde: nos aspectos fundamentais de saúde e doença, incluindo os programas referentes, na nutrição ajustada às várias fases do desenvolvimento humano, no planejamento familiar, nas doenças sexualmente transmitidas, no aleitamento materno, na motivação e condução da comunidade na avaliação de suas necessidades e problemas, no crescimento e desenvolvimento normal, na divulgação de informações sobre a utilização dos serviços de saúde, na atenção ao desenvolvimento da personalidade. No que diz respeito à proteção específica: uso de imunizações específicas, atenção à higiene pessoal, hábitos de saneamento do meio ambiente, desinfecção concorrente terminal. "Consideramos Serviço de Saúde os que tratam do exercício legitimado da medicina, da odontologia e outras atividades cujo fim explícito é expressar ou restaurar a saúde da população" (Singer Campos e Oliveira, 1998, p. 9).

Para Prevenção Secundária, Diagnóstico Precoce e Tratamento Imediato: participação no planejamento e na implementação dos programas de imunização, colaboração no desenvolvimento dos programas para detectar deficiências auditivas e visuais, câncer, malária, diabetes, hipertensão, etc; controle de doenças transmissíveis, como tuberculose, doenças venéreas, colaboração no desenvolvimento dos programas para a prevenção de acidentes. Limitação de incapacidade: enfermagem domiciliar após a alta 
hospitalar quando indicada, terapêutica completa, hospitalização, quando indicada. Limitação da incapacidade: enfermagem domiciliar após a alta hospitalar quando indicada, terapêutica completa, hospitalização, quando indicada.

Na Prevenção Terciária, Reabilitação: prover serviços terapêuticos de Enfermagem, tratamento das doenças comuns (diarréia, infecção das vias respiratórias superiores), auxiliar nos primeiros socorros e cuidados de emergência, acompanhamento e controle dos pacientes com alta do hospital (diabetes, desnutrição) e doenças crônicas como hipertensão, etc., proporcionar orientações e supervisão para a família no cuidado de um doente ou deficiente físico, prover assessoramento de saúde, como: alcoolismo, drogas, doenças mentais, adolescentes grávidas, etc., fornecer as referências apropriadas aos outros serviços ou gerências, coordenar o cuidado ou programas de Enfermagem com o de outros profissionais de saúde.

A equipe de trabalho deve conhecer as disponibilidades de saúde de sua comunidade e, uma vez que deve trabalhar com a população em seus domicílios, identificar suas necessidades e características socioeconômicas e culturais, o que the permite tomar atitudes para mobilizar recursos da comunidade e incrementar as atividades no propósito de minimizar os problemas de saúde vigentes (Araújo, 1995).

Segundo Kawamoto (1995), a ação educativa em saúde é um processo que objetiva capacitar indivíduos ou grupos para assumirem ou ajudarem na melhoria das condições de saúde da população. Os profissionais e a população devem compreender que a saúde da comunidade depende das ações oferecidas pelos serviços de saúde, como também do esforço da própria população através de conhecimentos, compreensão, motivação, reflexão e adoção de práticas de saúde.

Quando relacionamos educação e saúde, pensamos prontamente nas recomendações sobre cuidados pessoais (higiene, alimentação, etc.) que devemos assumir para evitar doenças. Manter a saúde parece, portanto, ser um problema exclusivamente individual, o qual pode ser facilmente resolvido pelas pessoas adequadamente educadas (Valla, 1994, p. 11).

Acredita-se que um dos fatores responsáveis pela crise sanitária brasileira é a falta de conhecimentos e de reflexões sobre os princípios de saúde, inclusive os básicos e simples. Assim, conforme Carvalho e Santos (2002, p. 39), "O direito à saúde não pode se consubstanciar em vagas promessas e boas intenções constitucionais, garantido por ações governamentais implantadas e implementadas oportunamente, mas não obrigatoriamente. O direito à saúde (arts. 6 e 196) é dever estatal que gera para o indivíduo direito subjetivo público, devendo o Estado colocar à sua disposição serviços que tenham por fim promover, proteger e recuperar a saúde". Por isso, consideramos que a realidade da saúde das pessoas é dinâmica, 
mutável e pode ser melhorada quando o indivíduo ou grupo analisa criticamente sua situação, propõe ações conjuntas, organiza-se para realizá-las e avalia sua eficácia.

Segundo o mesmo autor, a educação em saúde é uma ação básica de saúde importante quando estiver baseada na reflexão crítica do grupo, porque o princípio dessa educação é o desenvolvimento da consciência crítica das causas, dos problemas e das ações necessárias para a melhoria das condições.

No processo de educação em saúde haverá confronto e procura de um atendimento entre os conhecimentos técnicos (dos profissionais de saúde) com os da população (cultura popular). Os profissionais não devem impor os seus conhecimentos e desconsiderar a realidade em que vive a população a ser trabalhada, se isso acontecer, as medidas propostas poderão não ser adotadas, devido à incompatibilidade com a realidade (Kawamoto, 1995).

Todos os profissionais de saúde devem exercer a ação educativa em todo o momento e em qualquer lugar: no consultório médico, na sala de vacinas, no grupo de gestantes, etc. Para exercerem esta função educativa, é necessário que haja uma transmissão de conhecimento através de mecanismos de comunicação que facilite a compreensão e estimule a sua prática. Portanto, a atividade educativa não é um processo estático, pois a simples transmissão da informação não assegura mudanças significativas que levem a uma melhor qualidade de vida da população. É necessária uma reflexão crítica do indivíduo, do grupo e da equipe de saúde para, juntos, resolverem os problemas e modificarem essa realidade. Quando o indivíduo e o grupo entendem melhor o processo saúde/doença, espera-se diminuir a demanda por serviços curativos, uma vez que a população passa a utilizar-se de medidas gerais de controle de enfermidades preveníveis e aumentar a demanda por serviços preventivos regulares, tais como vacinação, controle de pré-natal, etc.

Na pesquisa quali-quantitativa que utiliza o método descritivo de caráter exploratório, como foi utilizada, conforme Polit (1995), abordagem qualitativa é quando se tem um plano estabelecido por onde o pesquisador conduz seu trabalho. Segundo o autor, nesta abordagem prioriza-se o destaque das falas, palavras escritas, o mundo empírico no ambiente natural obtendo os dados e disseminando os resultados.

A pesquisa quantitativa permite uma menor incidência de erros nos resultados, visto que sua abordagem oferece uma margem de dados estatísticos regulares, seguros e precisos na aplicação de noções básicas para contar e medir por meio do instrumento matemático, além de possibilitar uma interação entre o pensamento e a linguagem e o seu desenvolvimento mútuo, possuindo ainda a importância de mensurar, observar e representar 
extensivamente o objeto estudado, como também a interpretação dos fatos em suas diversas formas (Minayo, 1999).

Já a pesquisa exploratória-descritiva, de acordo com Gil (1995), tem por objetivo desenvolver, esclarecer e modificar conceitos e idéias em busca de formulações de problemas e hipóteses pesquisáveis para outros estudos e ao mesmo tempo faz a descrição das características de determinada população, fenômeno ou relação entre variáveis; para isto, são utilizadas técnicas significativas e padronizadas de coleta de dados.

O presente estudo foi realizado no Posto de Central de um município do Vale do Taquari - RS, uma instituição que atende toda a população do município, inclusive o interior, e cidades vizinhas. Nela encontra-se uma ampla área física, e conta com uma equipe multiprofissional composta por dois médicos ginecologistas, um pediatra, um cardiologista, um clínico geral, duas enfermeiras, uma auxiliar de enfermagem, duas secretárias e uma auxiliar de serviços gerais. É importante ressaltar que na área deste posto de saúde não há agentes comunitários de saúde atuando.

Fizeram parte da pesquisa $30 \%$ da população que retirou ficha para atendimento médico com clínico geral durante o mês de março de 2003, em que as mesmas autorizaram a realização da pesquisa. Para viabilizar a coleta de dados foi utilizado um questionário, com questões abertas e fechadas, relativas às questões norteadoras previamente estabelecidas para este estudo.

Considerando os aspectos éticos a pesquisadora informou aos sujeitos respondentes do questionário os objetivos dessa pesquisa, sendo assegurado, por meio do Consentimento Livre e Esclarecido, a confidencialidade e privacidade, a proteção da imagem, garantindo a não utilização das informações em prejuízo das pessoas. Segundo Goldim (2000), o consentimento informado tem quatro componentes principais: a informação, a compreensão, a capacidade e a voluntariedade, os quais devem ser claramente especificados para os sujeitos participantes.

Os dados foram analisados percentualmente. Após a aplicação e recolhimento dos questionários, foi iniciada a análise dos dados, de acordo com o universo de questionários respondidos. Os dados foram contabilizados de forma quantitativa, onde foram analisadas as questões fechadas. A análise qualitativa das questões abertas foram descritas conforme as respostas do participante, e os resultados foram apresentados em figuras.

Buscamos caracterizar o conhecimento da população em relação à prevenção e promoção da saúde, verificar se recebem orientações e ou informações sobre sua importância e o tipo de orientações recebidas. Inicialmente uma caracterização dos sujeitos participantes foi realizada, de modo que uma presença predominante do sexo feminino foi evidenciada. Destes sujeitos, a maioria possui idades entre 45 e 55 anos, nível de escolaridade 
de 1 grau incompleto. Quanto ao conhecimento destes em relação a prevenção da saúde, a grande maioria entende corretamente o que significa, mesmo com algumas opiniões diferentes. Já no que se refere à promoção da saúde, a grande maioria não sabe o que é, e nem faz idéia do que significa. Esta questão é preocupante, nos revela que a população está pouco orientada nesse sentido, caracterizando a procura do serviço de saúde em outro nível de atenção.

Em relação a campanhas de vacinação, feiras de saúde e palestras, observamos a falta de interesse e de motivação na população estudada. Apesar destas serem as principais ações na área da prevenção e promoção da saúde oferecidas à população, são pouco procuradas. Na questão referente ao que significa saúde, notamos uma mescla de opiniões, mas todas relacionadas ao bem-estar físico da pessoa. Apesar de saúde ter aparecido com muitos conceitos, não há uma unanimidade de opiniões para eles.

Outra questão preocupante é que a grande maioria dos entrevistados procura o serviço de saúde em âmbito curativo. A população sabe o que é prevenção, mas por algum motivo, seja falta de interesse, orientação ou educação em saúde, não procura o serviço em âmbito preventivo. Percebemos também que a maioria não participa de grupos de prevenção em saúde, muitas vezes, alegando falta de tempo. Já a minoria que freqüenta estes grupos são pessoas que sofrem por certas patologias, neste caso, hipertensão e diabetes, e estão ali para prevenir um malefício ainda maior.

A população recebe orientações sobre prevenção e promoção da saúde, porém, na maioria das vezes, esta é feita rapidamente pelo médico e não pela equipe de saúde como um todo, mas procura o serviço de saúde quando já está doente ou com algum sintoma. Mesmo nesse caso, as orientações fornecidas, são as mais importantes em relação à prevenção da saúde.

Em suma, a população entrevistada tem noção do que é prevenção em saúde, porém não participa das campanhas que são realizadas e procura o serviço de saúde apenas quando está doente, o que comprova que há uma carência de orientações sobre a importância da prevenção e sobre o que seja promoção da saúde, bem como a realização de um trabalho de motivação por parte das equipes multiprofissionais, com vistas a este enfoque no Processo saúde/doença.

Os resultados do presente estudo reforçam a convicção de que os profissionais que atuam na área de saúde pública devem voltar seus esforços para garantir maior qualidade na saúde da população, realizando um trabalho diversificado de educação em saúde. Os postos de saúde constituem um campo vastíssimo, em termos de pleno desenvolvimento de atividades e consolidação de orientações voltadas à prevenção e promoção da saúde. A equipe de trabalho possui um certo comando nestes locais, e 
tem plenos poderes para delineá-los e direcioná-los conforme as necessidades da população, considerando o planejamento de suas ações, na atuação de rotina no serviço.

Usar a dialética para buscar algum tipo de conceito sobre necessidades de saúde e modelo de intervenção, certamente utilizando o campo das múltiplas interpretações e o conhecimento multiprofissional, é um desafio bastante grande para uma administração municipal, que busca seguir os preceitos do Sistema Único de Saúde. Almeida (1998), comenta que "a saúde deve ser entendida em sentido mais amplo", como componente do conhecimento da população em busca de promoção de saúde, principalmente com vistas à atuação dos profissionais e da gerência dos Serviços de Saúde, que têm responsabilidade sobre os encaminhamentos, ações e principalmente das representações e do conhecimento adquirido sobre os cuidados com a saúde, principalmente indivíduos que procuram esse serviço sistematicamente.

\section{BIBLIOGRAFIA}

1. ALMEIDA, E.S., Castro, C.G.J., Vieira, C.A.L. Distritos Sanitários: concepção e organização. São Paulo: Faculdade de Saúde Pública da Universidade de São Paulo, 1998, vol. 1. (Série Saúde \& Cidadania).

2. ARAÚJO, Maria José Bezerra. Ações de Enfermagem em Saúde Pública. 4. ed. M. J. Bezerra Araújo Editora Ltda.

3. BEAGLEHOLE, R.; BONITA, R.; KAJELLSTRÖM, T. Epidemiologia básica. 2. ed. São Paulo: Santos, 2001.

4. BRASIL. Decreto-Lei n. 93.933, de 14 de janeiro de 1987. Resolve aprovar as seguintes diretrizes e normas regulamentadoras de pesquisa envolvendo seres humanos. Resolução n. 196/96 sobre pesquisa envolvendo seres humanos. Revista Bioética, vol. 4, n. 2, suplemento 1996.

5. BRASIL. Lei n. 8.080/90 - Lei Orgânica de Saúde, 19 de setembro de 1990.

6. BRASIL. Ministério da Saúde. Norma Operacional Básica - SUS n. 1/96. Diário Oficial da União, Brasília. 1996.

7. BRASIL. Ministério da Saúde. Norma Operacional da Assistência à Saúde - NOAS-SUS 01/2001. Diário Oficial da União, Brasília. 2001.

8. CAMPOS, Gastão Wagner de Souza. A saúde pública e a defesa da vida. São Paulo: Hucitec, 1991.

9. CARVALHO, Guido Ivan de; SANTOS, Lenir. Sistema Único de Saúde: comentários à Lei Orgânica da Saúde (Leis ns. 8.080/90 e 8.142/90), 3. ed. Campinas, SP: Unicamp, 2002. 
10. CECCIN, Ricardo Burg. Saúde e doença: reflexão para a educação da saúde. In: MEYER, D. E. (Org.). Saúde e sexualidade na escola. 2. ed. Porto Alegre: Mediação, 1998.

11. COHN, Amélia; ELIAS, Paulo Eduardo M. Saúde no Brasil: políticas e organização de serviços. 5. ed. São Paulo: Cortez: CEDEC, 2003.

12. DALLARI, Sueli Gandolfi. Municipalização dos serviços de saúde. São Paulo: Brasiliense, 1985.

13. . Os Estados brasileiros e o direito à saúde. São Paulo: Hucitec, 1995.

14. DEMO, Pedro. Metodologia Científica em Ciências Sociais. 2. ed. São Paulo: Atlas, 1992.

15. DEVER, G. E. A. A epidemiologia na administração dos serviços de saúde. São Paulo: Livraria Pioneira e editora, 1998.

16. DUSSAULT, Gilles. A gestão dos serviços públicos de saúde: características e exigências. Revista Administração de Saúde Pública. Rio de Janeiro, 26(2): 8-19, abr./jun. 1992.

17. EGRY, Emiko Yoshikawa. Saúde coletiva: construindo um novo método em enfermagem. São Paulo: İcone, 1986.

18. FIOCRUZ - Formulação de Políticas de Saúde Gestão em Saúde, Curso de Aperfeiçoamento para Dirigentes Municipais de Saúde, Universidade de Brasília, 1998.

19. FORATTINI, Oswaldo Paulo. Epidemiologia Geral. 2. ed. São Paulo: Arte Maciças, 1996.

20. GIL, Antônio C. Métodos e Técnicas de Pesquisa Social. 4. ed. São Paulo: Atlas, 1998.

21. Http://portalweb02.saude.gov.br/saude/visualizar_texto.cfm?idtxt=497. Acesso em 16 maio 2003.

22. JEKEL, J. E.; ELMORE, J. G.; KATZ, D. L. Epidemiologia, bioestatística e medicina preventiva. Porto Alegre: Artes Médicas, 1999.

23. KAWAMOTO, E. E.; SANTOS, M. C.H. Enfermagem Comunitária. São Paulo: Pedagógica e Universitária Ltda, 1995.

24. LEBRÃO, Maria Lúcia. Estudos da Morbidade. São Paulo: Universidade de São Paulo, 1995.

25. MINAYO, Maria Cecília de Souza. O desafio do conhecimento. 6. ed. Rio de Janeiro: Abrasco, 1999.

26. PEREIRA, Maurício Gomes. Epidemiologia, Teoria e Prática. Rio de Janeiro: Guanabara Koogan, 1995. 
27. PEREIRA, PAP, Necessidades Humanas - subsídios à crítica dos mínimos sociais. São Paulo: Cortez Editora; 2000.

28. POLIT, D. F. H.; BERNADETTE, P. Fundamentos de Pesquisa em Enfermagem. 3. ed. Porto Alegre: Artes Médicas, 1995.

29. REVISTA Ciência e Saúde Coletiva. 5(1), 163-178, 2000.

30. ROUQUAYROL, M. Z.; FILHO, Naomar de Almeida. Epidemiologia e Saúde. 5. ed. Rio de Janeiro: Médica e Científica Ltda., 1999.

31. SEIXAS JC, Sistema de Saúde: as necessidades de "saúde-doença". São Paulo; 1999. [Apostila do Curso de Pós-Graduação em Saúde Pública Faculdade de Saúde Pública da USP].

32. SINGER, P.; CAMPOS, O.; OLIVEIRA, E. M. Prevenir e Curar: o controle social através dos serviços de saúde. 3. ed. Rio de Janeiro: Forense Universitária.

33. VALLA, V. V.; STOTZ, E. N. Educação Saúde e Cidadania. Petrópolis/RJ: Vozes Ltda, 1994. 